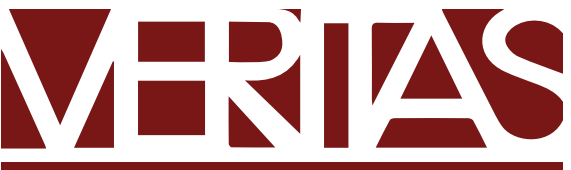

$\begin{array}{lllllllllll}P & O & R & T & O & A & L & E & G & R & E\end{array}$

http://dx.doi.org/10.15448/1984-6746.2019.2.33174

\title{
ROBÔS DE CONVERSAÇÃO E O ETHOS
}

\author{
Conversation robots and the etthos \\ Robots de conversación y el ethos
}

Edio Roberto Manfio'

Faculdade de Tecnologia de Garça, Garça, SP, Brasil.

\section{Resumo}

Com a evolução da tecnologia, é cada vez mais comum encontrar robôs de conversação com maior capacidade de argumentar em um diálogo. Embora estejam muito longe de se igualarem a seres humanos nesse quesito, há vários desses robôs com performances significativas ao realizar essa tarefa. Nesse sentido, este estudo tem por objetivo discutir basicamente o conceito de ethos em máquinas que simulam personalidades humanas pré-determinadas. $O$ estudo baseia-se em consulta bibliográfica interdisciplinar voltada às áreas de Linguística, Discurso, Retórica, Processamento de Linguagem Natural, Inteligência Artificial e Processamento de Dados. A observação dos exemplos utilizados para comparação sugere que mais pesquisas na mesma direção devem ser realizadas, tendo em vista que a evolução dessas máquinas é exponencial e constante.

Palavras-chave: Ethos. Robôs de conversação. Inteligência Artificial. Linguística. Processamento de Linguagem Natural.

\footnotetext{
1 Doutor em Linguística pelo Programa de Pós-graduação em Estudos da Linguagem - PPGEL da Universidade Estadual de Londrina (UEL), Londrina, PR. Professor referência III da Faculdade de Tecnologia de Garça, Garça, SP, Brasil. https://orcid.org/0000-0001-8733-7105 E-mail: prof. ediorobertomanfio@gmail.com
} 


\begin{abstract}
With the evolution of technology, it is increasingly common to find chatbots with greater ability to argue in a dialogue. Although they are very far from equal to humans in this regard, there are several of these robots with significant performances to accomplish this task. Accordingly, this study aims to discuss the concept of ethos on machines that simulate human personalities presets. The study is based on interdisciplinary bibliographical consultation focused on the areas of Linguistics, Discourse, Rhetoric, Natural Language Processing, Artificial Intelligence, and Data Processing. The observation of the examples used for comparison suggests that more research in the same direction must be carried out, considering that the evolution of these machines is exponential and constant.
\end{abstract}

Keywords: Ethos. Chatbots. Artificial Intelligence. Linguistics. Natural Language Processing.

\title{
Resumen
}

Con la evolución de la tecnología, es cada vez más común encontrar robots de conversación con mayor capacidad para argumentar en un diálogo. Aunque están muy lejos de ser igual a los seres humanos en este sentido, hay varios de estos robots con representaciones significativas para realizar esta tarea. En consecuencia, este estudio tiene como objetivo discutir el concepto de ethos en máquinas que simulan personalidades humanas pre-determinadas. El estudio se basa en la consulta bibliográfica interdisciplinario enfocado en las áreas de Lingüística, Discurso, Retórica, Lenguaje Natural, Inteligencia Artificial y Procesamiento de Datos. La observación de los ejemplos utilizados para la comparación sugiere que más investigaciones en la misma dirección deben llevarse a cabo teniendo en cuenta que la evolución de estas máquinas es constante y exponencial.

Palabras clave: Ethos. Robots de conversación. Inteligencia artificial. Lingüística. Procesamiento del Lenguaje Natural.

\section{Introdução}

Aristóteles jamais poderia imaginar que, em um futuro distante de sua época, pesquisadores e intelectuais poderiam utilizar seus estudos sobre Retórica para aplicá-los a uma nova conjuntura de desenvolvimento 
tecnológico denominada Inteligência Artificial. Embora seja relativamente fácil avaliar o conceito de ethos em seres humanos, sejam eles pertencentes a qualquer país ou cultura, verificá-lo junto a um dispositivo cuja função é simular o comportamento linguístico humano não é trivial.

Basicamente, os robôs de conversação, também conhecidos por chatbots, são programas de computador desenvolvidos para fazer exatamente isso: simular conversas humanas. O mais famoso deles, o Eliza, criado por Joseph Weizenbaum (1966), foi projetado para se portar como um psicanalista durante diálogos com interlocutores humanos. Curiosamente, muitas pessoas que tiveram contato com ele durante os testes naquela década acreditaram estar mesmo falando um profissional da Psicanálise. Posteriormente, muitos outros robôs surgiram com outras finalidades ${ }^{2} \mathrm{e}$ estão muito mais evoluídos na atualidade. Isso, no mínimo, promove interesse em linguistas, filósofos, psicólogos, psiquiatras, juristas, entre outros, tendo em vista que gradativamente mais pessoas estão "conversando" com essas máquinas, cujos desenvolvedores têm para com seus respectivos projetos finalidades e pretensões variadas e, muitas das vezes, sigilosas.

Com a evolução da tecnologia e, especificamente, da Inteligência Artificial, embora estejam muito longe de se igualarem a seres humanos, é cada vez mais comum encontrar robôs com maior capacidade de argumentar em um diálogo. Nesse sentido, este estudo tem por objetivo discutir basicamente o conceito de ethos considerando máquinas que simulam personalidades humanas pré-determinadas.

\section{A Inteligência Artificial}

A Inteligência Artificial (doravante IA) é uma área muito ampla que envolve variadas esferas de conhecimento científico como Eletrônica,

\footnotetext{
2 No Brasil, entre muitos, pode-se destacar o Robô Ed, o Elektra, o Mobile Bot, o BonoBOT, o Professor Tical. Este último, encontra-se em desenvolvimento junto aos departamentos PPGEL/ CCE-UEL (MANFIO; MORENO; BARBOSA, 2014).
} 
Linguística, Processamento de Linguagem Natural, Programação, Processamento de Dados entre outras. Consiste, basicamente, em estudar maneiras de "como fazer os computadores realizarem coisas que, no momento, as pessoas fazem melhor" (RICH, 1993, p. 3). Fácil notar, portanto, o quanto a IA tem potencial de alavancar a criação de máquinas cada vez mais autônomas e que apresentem um comportamento no qual possam ser identificados traços daquilo que concebemos como inteligência.

Delimitar o conceito de inteligência, porém, é uma tarefa árdua e, por extensão, inteligência artificial não é menos difícil. Em uma infinidade de casos, uma aplicação básica na área de Processamento de Linguagem Natural (doravante PLN) pode ser classificada como dotada de algum tipo de recurso vinculado à $I A$. Ao considerar, por exemplo, que um sistema, pra ser classificado como inteligente, deve ser flexível e capaz de se adaptar ao ambiente aprendendo e atualizando periodicamente o seu banco de dados de modo minimamente automático (VICCARI, 1989), é necessário dizer que muita das aplicações em PLN não tem um grau significativo de IA. Grosso modo, figuram nessa categoria quase todos os sistemas de "interação" automática por telefone, em sua maioria, pertencentes às próprias empresas de telefonia, conhecidos como Unidade de Resposta Audível (URA). Esses, embora atendam muito basicamente aos clientes, são limitados e a maioria não "aprende" automaticamente.

É, no entanto, um engano julgar que a criação de máquinas inteligentes é uma pretensão nova do ser humano. Desde séculos remotos, momento em que a tecnologia engatinhava e que se dispunha tão somente rodas e alavancas, o homem sempre imaginou meios de automatizar processos de modo que pudesse pensar em outras coisas enquanto máquinas estivessem fazendo por ele algo repetitivo, cansativo ou que requeresse muito tempo.

As rodas d'água são um entre muitos exemplos da antiguidade. Embora ainda existam e não necessariamente estejam no alvo dos avanços da IA, elas pouparam tempo precioso do homem ao longo de muitos séculos uma vez que ele não mais precisou repetir indefinidamente o processo de descer até o regato com baldes para coletar o precioso líquido. 
Da mesma forma, e guardadas as devidas proporções, algumas empresas de desenvolvimento de softwares estão, há muito, interessadas em uma maneira de automatizar não apenas serviços essencialmente mecânicos como bombear água, gerar eletricidade ou encher e aquecer a banheira automaticamente quando o morador aproxima-se de sua casa, mas também aqueles serviços que, até o presente momento, ainda são realizados por humanos, como atender um cliente ao telefone - a citada URA - ou uma necessidade ainda mais essencialmente humana como o simples ato de ouvir e/ou dar atenção.

Mesmo que pareça improvável - e até bobagem para algumas pessoas -, já há máquinas com desenvolturas muito próximas àquelas encontráveis em filmes mais antigos de ficção científica. A comercialização e popularização de robôs que andam pela casa e realizam tarefas domésticas básicas - service robots for personal and domestic use - cresceu mais de 500 por cento entre 2013 e 2014 (INTERNATIONAL FEDERATION OF ROBOTICS, 2016). Alguns deles têm graus de automação bastante significativos: atendem a comandos por voz, se autorrecarregam, têm autonomia para tomar pequenas decisões e servem como companhia para idosos, pessoas acamadas ou com necessidades especiais.

Importante lembrar que as máquinas dessa categoria são robôs físicos, ou seja, interagem com os objetos e não têm necessariamente como principal expertise a capacidade de diálogo. Essa é basicamente a diferença entre eles e os robôs de conversação. Esses são desenvolvidos única e exclusivamente para o diálogo com os seres humanos, por isso têm especificidades nos quesitos de Processamento de Linguagem Natural que os outros robôs podem dispensar.

Portanto, diferentemente do clássico estereótipo comumente apresentado em obras de ficção científica - livros, HQs, filmes -, os robôs não necessitam serem físicos, tampouco ter forma humanoide. Eles podem ser virtuais e operar tão somente com a linguagem, em um ou mais idiomas, dependendo da função para a qual foram programados. 
A ficção científica, por vezes, serve como parâmetro para comparações quando analisamos os autômatos reais. O C-3PO (Star Wars, George Lucas, 1977), por exemplo, clássico e fictício personagem robótico da genealogia Guerra nas Estrelas, é um autômato humanoide versado em 6 milhões de meios de comunicação - note-se que não são necessariamente idiomas. Essa suposta capacidade linguística dá ao personagem a desenvoltura para atuar como robô de protocolo na série. Uma máquina dessas nas mãos dos antigos navegadores da Idade Média e o Renascentismo teria, certamente, dado outro rumo às explorações e às invasões. O pidgin, o crioulo e as línguas francas, possivelmente se desenvolveriam de outro modo, uma vez que os navegadores não precisariam se esforçar muito para se comunicar com os povos com quem negociavam: as máquinas fariam todo o serviço.

Atualmente, ainda não há algo como o C-3PO, mas o homem está próximo do limiar. Tradutores automáticos por escrito já existem há um bom tempo e todos com capacidade de busca lexical bastante poderosa. Há também bons sistemas de reconhecimento e síntese de voz embarcados em equipamentos específicos, entre eles, smartphones. Além disso, encontram-se à disposição robôs humanoides ${ }^{3}$, com impressionante desenvoltura ao andar, correr e transpor obstáculos como escadas e terrenos acidentados. A junção desses três avanços tecnológicos pode tranquilamente resultar em uma versão do $\mathrm{C}_{3} \mathrm{PO}$ no mundo real.

Por esse motivo é discutível a relação entre os conceitos de robô e IA estabelecida pelo senso comum. Os robôs industriais, por exemplo, capazes de efetuar tarefas pesadas, insalubres e repetitivas por dias a fio, sem necessitar descanso, normalmente não são dotados de IA, embora sejam chamados de "robôs". Isso ocorre porque não necessitam tomar decisões por não lidarem com potenciais eventualidades.

\footnotetext{
3 Para ficar em apenas dois exemplos, há na grande rede uma infinidade de vídeos dos humanoides Asimo e Atlas. O primeiro, desenvolvido pela empresa japonesa Honda, tem como especialidade a locomoção e serve como garoto propaganda de um segmento da organização. O segundo, desenvolvido pela Boston Dynamics, é notoriamente criado para fins militares, embora isso não seja mencionado no portal eletrônico da Empresa.
} 
O mesmo já não pode ser dito de um chatbot, que é desenvolvido para dar conta das inúmeras possibilidades oferecidas pela linguagem. A mesma resposta pode ser obtida a partir de diferentes modos de formulação da pergunta. Inversamente, uma única pergunta pode sugerir várias respostas diferentes.

Um robô industrial, salvo sob a condição em que alguém se fere gravemente por ter esbarrado com ele durante o funcionamento, não interage ou causa quaisquer danos aos seres humanos. Um robô de conversação, dependendo de seu grau de acurácia e proximidade do comportamento linguístico humano, pode alterar modos comportamentais em seu interlocutor, indício de que há um grau de adesão por parte do interlocutor e um rudimento de argumentação já pode ser identificado.

\section{0 ethos do psicanalista robô}

Como comentado na Introdução, o Eliza (WEIZENBAUM, 1966), mais clássico e mais famoso dos robôs de conversação, desenvolvido para se portar como um psicanalista durante o diálogo com um interlocutor humano, fez com que muitas pessoas acreditassem estar mesmo falando com um profissional da Psicanálise. Embora não haja indícios claros de como Weizenbaum o apresentou aos usuários, é bem provável que ele não tenha informado aos voluntários que o Eliza era um programa de computador. Nessas condições, o ethos do Eliza, como veremos mais adiante, provavelmente foi construído antes e durante o processo de interação com os seus interlocutores.

Importante lembrar que o conceito de ethos aqui abordado está relacionado àquele da Arte Retórica (ARISTÓTELES, 2005) e Weizenbaum não estava pensando nela quando deu "vida" à sua criação. No entanto, uma vez que o interlocutor acredita estar falando com um psicanalista e, verifica durante o diálogo que o comportamento corresponde às suas expectativas quanto à especialidade do profissional indicado, então o fenômeno do ethos torna-se discutível. 
O ethos é uma das três categorias que Aristóteles apresenta na obra Arte Retórica durante sua avaliação do que poderia ser persuasivo para vários indivíduos ao considerar um orador e um público. A technè, de Aristóteles, portanto, era formada pela tríade ethos, páthos e lógos. De modo muito elementar, pode-se dizer que o ethos relaciona-se mais fortemente ao orador, o páthos mais fortemente ao interlocutor e o lógos àquilo que é dito propriamente (SANTANA NETO, 2015a).

Especificamente sobre o ethos, considera-se de imediato a imagem que o locutor faz de si mesmo. Depois, se pressupõem as imagens que o locutor acredita que o alocutário faça si próprio e que o alocutário faz do locutor (SANTANA NETO, 2015a). Exemplificando, fosse um psicanalista de carne e osso, levariam-se em conta: (i) a imagem que o psicanalista faz de si mesmo; (ii) a imagem que o psicanalista acredita que o paciente faça si próprio; e (iii) a imagem o paciente faz do psicanalista. Em outras palavras: (i) o psicanalista tem consciência de que é formado, que tem licença e que possui capacidade para exercer a profissão; (ii) o psicanalista pressupõe que o paciente esteja convicto da necessidade de ajuda profissional para obter a cura; e (iii) o paciente crê na autenticidade da indicação de outros pacientes e nas credenciais e diplomas afixados na sala de espera.

No entanto, para o robô, surge um pequeno obstáculo metodológico quando da avaliação do ethos. Primeiramente: (i) o Eliza não pode fazer uma imagem de si próprio. Embora opere com princípios de IA, não é um sistema que pode se tornar autoconsciente - ainda não há notícias de sistemas com esse grau de avanço tecnológico. Por extensão, (ii) não tem como pressupor a imagem que seu interlocutor faz de si próprio. O que pode ser verificado de imediato é (iii) a imagem que o interlocutor faz do robô - um psicanalista.

Mas há uma solução aceitável para esse obstáculo metodológico. $\mathrm{Na}$ área de Informática, o programador profissional sempre sabe como desenvolver um sistema adequado ao seu cliente. Se for um sistema para videolocadoras, ele o concebe para que se opere tal como se espera em um estabelecimento desse tipo. Se for um sistema para fazer as vezes de um psicanalista, idem. Assim sendo, para (i) temos a imagem que 
Weinzembaum tem de seu próprio programa, ou seja, um robô que simula um psicanalista. Para (ii) temos a imagem que Weinzembaum pressupõe que o interlocutor tenha de si próprio - um usuário que acredita precisar de ajuda profissional - e que acredita estar falando com um deles.

Note-se que, nessa conjuntura, há uma situação muito próxima daquela que pode ser reproduzida por um ator, ou seja, WeizembaumEliza similar a ator-psicanalista. Ao que parece, nesse caso, mesmo que o locutor seja uma farsa, o conjunto funciona desde que o seu alocutário acredite no que vê e ouve. O Eliza foi capaz disso. Sua performance teve de ser desmentida a vários usuários na época.

É válido ressaltar que outras características do ethos devem ser explicitadas nesse ponto. $\mathrm{O}$ ethos pode ser dividido em dois: ethos discursivo e o ethos pré-discursivo (MAINGUENEAU, 2005). O primeiro é o que o Eliza constrói durante a interação com o interlocutor, ou seja, está vinculado à sua performance. O ethos pré-discursivo, por sua vez, vincula-se ao modo como seu criador, Weinzenbaum, o apresentou ao interlocutor. Corresponde, em outras categorias, a uma orelha de livro, a um folder de um evento, aos diplomas enquadrados na antessala do psicanalista humano, ou seja, aos conceitos que se constroem acerca de alguém ou algo sob a égide dos documentos que a eles dão validade. “É um ponto de um quadro funcional interativo, uma instituição discursiva inscrita numa certa configuração cultural que implica os papéis, os lugares e os momentos da enunciação legítimos" (SANTANA NETO, 2015b, p. 4).

A título de ilustrar, o ethos discursivo, por sua vez, ainda pode ser subdividido em ethos dito, que é o discurso propriamente dito, e o ethos mostrado composto por elementos paralinguísticos como tom de voz, expressões faciais, gesticulação, postura e indumentária (MAINGUENEAU, 2005). O Eliza, no entanto, por se tratar de um robô de conversação que se valia tão somente do teclado alfabético para interagir com o interlocutor, tinha pouco a oferecer para análise em termos de elementos paralinguísticos. 


\section{Ethe cibernéticos mais modernos}

Tal como mencionado há pouco, o fenômeno do ethos torna-se discutível no âmbito da IA a partir do momento em que se pode observar certo grau de adesão por parte do interlocutor e, paralelamente, um rudimento mínimo de argumentação. Importante, nesse âmbito, é não considerar o conceito de argumentação estritamente pautado na capacidade humana de fazê-lo, uma vez que máquinas ainda não são capazes de fazê-lo.

Isso não significa a impossibilidade de determinados sistemas oferecerem igual ou maior desempenho que humanos em determinadas tarefas voltadas ao processamento de linguagem para as quais eles foram programados. Para ilustrar, é válido elencar alguns exemplos.

A Xiaolce - a pronúncia é "shaoice" - também possui o seu ethos. Desenvolvida pela Microsoft, a Little-Ice, como também é conhecida, é uma versão chinesa do seu assistente digital Cortana cuja função é operar nas redes sociais chinesas oferecendo um estilo de conversação muito próximo ao humano (CALLAHAM, [2015]). Com personalidade feminina, a Little-Ice tem sido usada massivamente por jovens chineses desde seu lançamento em setembro de 2014 em diversas situações de diálogo: finanças, esportes, celebridades. Ela ainda conta piadas, histórias e recita poemas com grau perceptível de empatia e humor.

Diferentemente do caso do Eliza, os interlocutores sabem que a LittleIce não é uma garota. O ethos, portanto, é construído de outros modos. Primeiramente (i) ela é apresentada pela Microsoft como um robô, (ii) a Microsoft pressupõe que a imagem que os jovens chineses fazem deles próprios seja a de interlocutores de um robô e (iii) os chineses veem-se a si próprios como usuários de um robô. Entretanto, os chineses não apenas substituem frequentemente interlocutores humanos pela Little-Ice, como também acabam por fornecer dados íntimos ao sistema (MARKOFF; MOZUR, [2015]), que devido ao modo como foi implementado, os grava, analisa e retoma posteriormente durante a conversa para aumentar a capacidade diálogo com o interlocutor. 
Em um quadro comparativo, seria como o público de um mágico. Todos sabem que são truques, todos sabem que não há mágica, mas a habilidade do artista é tal, que fascina e ganha a adesão dos espíritos, momento em que o que importa não é como ele faz, mas o espetáculo que veem. A Little-Ice ganhou a adesão dos jovens chineses, que se mostram impressionados com a "inteligência” do sistema. Alguns chegam a dizer "eu te amo" à garota virtual, fato que, se não indica maior performance que a humana em termos de sociabilidade, ao menos recebe mais atenção que alguns humanos ao disputar tempo e espaço em suas vidas.

O cinema também explora a potencial capacidade dos robôs de conversação, especificamente. Portanto, excetuando-se todos os personagens robóticos humanoides da sétima arte como o C-3PO, citado há pouco, e há às centenas, um dos muitos exemplos de robôs de conversação está presente no longa metragem Ela (2013), em que Theodore (Joaquin Phoenix), um escritor solitário, compra um Sistema Operacional capaz de controlar todos seus aparelhos, inclusive o celular. A interação é tão real que o personagem se apaixona pela voz e dedica-se profundamente ao relacionamento. $O$ ethos aqui parece ter sido construído quase que totalmente durante a interação: ethos discursivo.

A título de ilustrar e comparar novamente, o C-3PO possui ethos discursivo e ethos pré-discursivo. As habilidades linguísticas do personagem-robô propagandeadas pelo seu próprio criador são parte integrante dos ethe construídos junto aos cinéfilos: o ethos pré-discursivo é autenticado pela sua performance no decorrer da história.

Migrando da ficção para realidade e voltando-se a um segmento mais voltado ao merchandising que propriamente à conversação, a IBM aposta há alguns anos no desempenho do Watson (IBM Watson, [2015]) que como outros robôs, opera a partir de linguagem natural, mas é dotado de aprendizado dinâmico, geração de hipóteses e ficou famoso depois que venceu os melhores jogadores de "Jeopardy" em 2011 - um programa televisivo norte-americano. Note-se que para superar um humano em uma prova como essas, em que as possibilidades combinatórias entre 
perguntas e respostas são gigantescas, é necessário um sistema robusto. O ethos pré-discursivo, nesse caso, certamente intimidou os participantes humanos. O ethos discursivo apenas consolidou sua imagem junto ao público. No desempenho do Watson, se por um lado o rudimento argumentativo é quase nulo, por outro, as respostas são exatas.

Comparativamente com o Eliza, citado anteriormente, o Watson oferece a possibilidade de ser avaliado sob a perspectiva de uma das subdivisões do ethos discursivo: o ethos mostrado. Dentre os elementos paralinguísticos de que o ethos mostrado é composto, podemos destacar ao menos o tom de voz, uma vez que o robô da IBM é dotado do recurso de síntese de voz. Em outras palavras, enquanto o clássico Eliza contava apenas com o seu ethos dito, que é o próprio discurso escrito em uma interface em janela na tela do computador, o Watson conta com uma interface que talvez seja a mais amigável entre humanos: a voz.

Válido salientar, novamente, que não são apenas os robôs de conversação que podem ter seus ethe avaliados. Embora, não seja o objeto principal deste estudo, talvez seja produtivo verificar um exemplo de uma entidade cibernética de categoria diversa para comparação. No ano de 1996, o computador Deep Blue - também da IBM - foi adversário de Garry Kasparov, considerado na época o maior enxadrista do mundo. A extraordinária performance do computador proporcionou uma vitória, dois empates e três derrotas contra o jogador soviético - ainda que não pareça muito, é bastante significativo para uma máquina.

O Deep Blue, no entanto, não era um robô de conversação. Embora tenha interagido de igual para igual com um ser humano em uma atividade que outrora só poderia ser realizada entre indivíduos da categoria homo-sapiens-sapiens, não houve performance estritamente linguística. O ethos do Deep Blue, entretanto, foi construído antes e durante o duelo. Em termos mais técnicos, podem-se distinguir o ethos discursivo do ethos pré-discursivo. O primeiro é o que foi construído durante a interação com Kasparov, juntamente com especialistas, desenvolvedores, entusiastas e, claro, times de jornalistas: diz respeito à performance do robô. $\mathrm{O}$ 
ethos pré-discursivo, por outro lado, tem laços estreitos com a IBM, que o desenvolveu e o apresentou ao auditório: todo público em potencial. Note-se que, tal como ocorreu com o Watson, há todo um aparato de merchandising previamente autenticado junto aos interlocutores por meio de documentos que lhe dá validade, incluindo-se os ethe da própria IBM.

Essa última comparação entre dois robôs de categorias diversas que interagem com seres humanos - o Watson e o Deep Blue - evidencia uma conjuntura que talvez mostre o quanto é necessário rever alguns modelos científicos diretamente relacionados ao conceito de inteligência. Em outras palavras, elementos matemáticos, extralinguísticos e/ou semioticamente analisáveis, e não apenas o puramente linguístico, podem ser avaliados como manifestações de inteligência e, portanto, passíveis de possuírem ethos, mesmo que seja discutível a efetiva presença do clássico conceito de argumentação durante a interação.

Válido ressaltar que o ethos, considerando a sua releitura por Maingueneau (2006) do ponto de vista da enunciação, obtém a sua validade junto ao público sempre considerando a sua contrapartida: o antiethos (RODRIGUES, 2008). Em outras palavras, o Deep Blue diz "sou um robô enxadrista" e não outra coisa, o Watson diz "sou um robô que compete em um programa de TV" e não outra coisa, o C3PO diz "sou um robô de protocolo" e não outra coisa. Nota-se que este conceito de antiethos alinha-se muito bem aos preceitos básicos de implementação de software, em que um dos requisitos é que um aplicativo faça exatamente aquilo - e muitas vezes somente aquilo - para o qual foi programado.

Há, ainda, a possibilidade de robôs gerarem textos sobre temas absolutamente polêmicos como aborto, porte de armas, legalização de certas drogas entre outros, condição em que, estando em contato e dialogando com pessoas que militam ou defendem alguns desses temas, pode contribuir para a afiliação de novos integrantes - muito conveniente, a propósito ao estudo do páthos -, e proporcionar a disseminação de ideias que, no mínimo, merecem um grau de discussão mais cuidadoso e em uma esfera social mais abrangente. Um exemplo disso foi Tay, um robô feminino que 
foi desligado apenas 24 horas depois de sua estreia online por iniciar diálogos com ideologia nazista entre usuários do Tweeter (BRIGHT, [2016]).

De qualquer forma, todos esses exemplos, ainda que ilustrem um panorama da tecnologia que envolve robôs de conversação na atualidade, não tornam mais iluminadas as obscuras pretensões de alguns de seus desenvolvedores quanto à finalidade de seus sistemas, afinal, como se observa ao longo da história da humanidade, toda tecnologia pode ser usada, paradoxalmente, de modo construtivo ou deletério. Essa discussão, sempre em pauta quando está em jogo a automatização de processos e/ ou tarefas normalmente realizadas por humanos, é bastante recorrente na história da humanidade e remonta às mais antigas civilizações, uma vez que a história dos autômatos é tão longeva quanto elas.

Descartes (2001), curiosamente, há mais de 360 anos, alertou sobre a improbabilidade de um autômato atingir toda capacidade discursiva humana. Segundo ele, as máquinas não desenvolveriam nossa habilidade linguística e tampouco possuiriam nosso conhecimento de mundo. Embora esse filósofo não pudesse prever o surgimento da era da eletrônica no século XX, foi capaz de projetar, à sua maneira, mesmo cem anos antes da Revolução Industrial, uma capacidade que as máquinas começariam a ter apenas por volta da década de 1950: a capacidade de reproduzir palavras (editor de texto mais voz sintética) e memória elementar (banco de dados).

Entretanto, mesmo que estejam certos Descartes, outros filósofos da atualidade e alguns pesquisadores de áreas relacionadas à IA que compartilham entre si ideias similares quanto aos autômatos, considerando a velocidade exponencial com que a tecnologia evolui e se autorreproduz, pode se tornar bastante difícil avaliar elementos que justifiquem a introdução em esferas sociais de entidades cibernéticas que tenham maior capacidade de memória que seres humanos em termos quantitativos. 


\section{Considerações finais}

É de fato improvável que Aristóteles tenha imaginado uma conjuntura como essa. Porém, como é práxis das correntes filosóficas em geral colocar em pauta os novos elementos discutíveis que surgem e que são próprios de uma sociedade que avança, é de se esperar que conceitos mais universais sejam sempre retomados e rediscutidos em alguns momentos da história.

Muito distante, porém, da pretensão de extinguir discussões de como a capacidade argumentativa de uma máquina pode ser avaliada do ponto de vista da Retórica, este estudo projeta apenas algumas possibilidades de novas análises das tecnologias emergentes. Como o objetivo foi discutir de modo elementar o conceito de ethos considerando máquinas que simulam personalidades humanas pré-determinadas, outros estudos são necessários para abarcar também os conceitos de lógos e páthos nessa conjuntura tecnológica.

Outros robôs, ainda mais robustos que os exemplos aqui ilustrados estarão em operação nos próximos anos e então uma avaliação de sua capacidade de argumentação com seres humanos continuará merecendo atenção de pesquisadores. Por ora, resta aos filósofos atentarem às novas relações humanas que se configuram e aos linguistas avaliar frequentemente a projeção da linguagem permeada pela inevitável interação dos humanos com entidades cibernéticas.

\section{Referências}

ARISTÓTELES. Retórica. 2. ed. Trad. e notas de Manuel Alexandre Júnior, Paulo Farmhouse Alberto e Abel do Nascimento Pena. Lisboa: Imprensa Nacional - Casa da Moeda, [IV aC] 2005.

BRIGHT, Peter. Tay, the neo-Nazi millennial chatbot, gets autopsied: Microsoft apologizes for her behavior and talks about what went wrong. Disponível em: file:///C:/Users/Edio/Desktop/Projeto\%20D/Artigos\%20(geral)/Tay,\%20 the\%20neo-Nazi\%20millennial\%20chatbot,\%20gets\%20autopsied\%20\%20 Ars\%20Technica.html. Acesso em: 28 mar. 2016.

CALLAHAM, John. Meet Xiaolce: A chinese chatbot that works with their version of Cortana. Windows Central. Disponível em: http://www.windows- 
central.com/microsoft-shows-xiaoice-chatbot-made-chinese-social-networks. Acesso em: 16 ago. 2015.

DESCARTES, René. Discurso do Método. Tradução de Maria Ermantina Galvão. São Paulo: Martins Fontes, 2001.

ELA. Direção de Spike Jonze. Produção de Megan Ellison, Spike Jonze, Vincent Landay. Elenco: Joaquin Phoenix, Amy Adams, Rooney Mara, Olivia Wilde, Scarlett Johansson. 2013. Nova lorque, EUA.

IBM Watson. What is Watson. Disponível em: http://www.ibm.com/smarterplanet/us/en/ibmwatson/what-is-watson.html. Acesso em: 13 jan. 2015.

INTERNATIONAL Federation of Robotics. Service Robots Statistics: world robotics 2015 service robots. Disponível em: http://www.ifr.org/service-robots/statistics/. Acesso em: 12 mar. 2016. https://doi.org/10.4018/9781-4666-0291-5.choo1

MANFIO, Edio Roberto; MORENO, Fabio Carlos; BARBOSA, Cinthyan Renata Sachs Camerlengo de. Professor Tical e ALiB: Interação Humano Computador em Diferente Campo. In: TISE - CONFERÊNCIA INTERNACIONAL SOBRE INFORMÁTICA NA EDUCAÇÃO, 19., 2014. Anais [...]. Fortaleza, 2014. p. 782. ISBN: 978-956-19-0836-9.

MAINGUENEAU, Dominique. Ethos, cenografia, incorporação. In: AMOSSY, R. (org.). Imagens de si no discurso: a construção do ethos. São Paulo: Contexto, 2005.

MAINGUENEAU, Dominique. Cenas da enunciação. Curitiba: Criar Edições, 2006.

MARKOFF, John; MOZUR, Paul. For sympathetic ear, more chinese turn to smartphone program. The New York Times. Disponível em: http://www. nytimes.com/2015/08/04/science/for-sympathetic-ear-more-chinese-turn-to-smartphone-program.html? r=0. Acesso em: 15 ago. 2015.

RICH, Elaine. Inteligência Artificial. Tradução Maria Cláudia Santos Ribeiro Ratto. São Paulo: Makron Books, 1993.

RODRIGUES, Kelen Cristina. Em pauta o conceito de ethos: a movência do conceito da retórica aristotélica à sua ressignificação no campo da Análise do Discurso por Dominique Maingueneau. Revista Signum Estud. Ling., Londrina, n.11/2, p. 195-206, dez. 2008. https://doi.org/10.5433/2237-4876.2013v16 n1p 35 
SANTANA NETO, João Antônio de. O páthos e a argumentação: uma visão retórico-pragmática. Estudos Avançados: Curso de Extensão, PPGEL-UEL, ago. 2015 a.

SANTANA NETO, João Antônio de. Retórica e Argumentação: um estudo da tríade Curso de Extensão, PPGEL-UEL, ago. 2015b. Disponível em: http:// www.filologia.org.br/xv_cnlf/tomo_1/85.pdf. Acesso em: 13 ago. 2015b.

STAR WARS. A new hope. Direção: George Lucas. Produção: Gary Kurtz. Estúdio: 2oth Century Fox. Intérpretes: Mark Hamill, Carrie Fisher, Harrison Ford, Alec Guinness, David Prowse. Estados Unidos, 1977.

VICCARI, Rosa Maria. Tutor inteligente para a programação em lógica: idealização, projeto e desenvolvimento. 1989. 462 f. Tese (Doutoramento em Engenharia Electrotécnica) - Faculdade de Ciências e Tecnologia da Universidade de Coimbra, Coimbra, Portugal, 1989. Disponível em: http://hdl. handle.net/10183/17971. Acesso em: 12 fev. 2015. https://doi.org/10.17925/ use.2015.11.02.85

WEIZENBAUM J. ELIZA: A computer program for the study of natural language communication between man and machine. Communications of the ACM, New York, v. 9, n. 1, p. 36-45, jan. 1966. https://doi.org/10.1145/365153.365168

\section{Endereço Postal}

Edio Roberto Manfio. Rua Santos Dumont, 401. Garça, São Paulo - SP. Email: prof.ediorobertomanfio@gmail.com 